\title{
Evidence of the validity of a novel version of the computerized cognitive screening battery CompCog
}

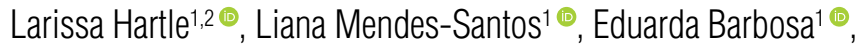 \\ Giulia Balboni ${ }^{\odot}{ }^{\circ}$, Helenice Charchat-Fichman ${ }^{1 \odot}$
}

\begin{abstract}
Although the availability of the computer-based assessment has increased over the years, neuropsychology has not carried out a significant paradigm shift since the personal computer's popularization in the 1980s. To keep up with the technological advances of healthcare and neuroscience in general, more efforts must be made in the field of clinical neuropsychology to develop and validate new and more technology-based instruments, especially considering new variables and paradigms when compared to paper and pencil tests. Objective: This study's objective was to produce concurrent validity evidence of the novel version of the computerized cognitive screening battery CompCog. Methods: Participants performed a traditional paper and pencil neuropsychological testing session and another session where CompCog was administrated. The data of a total of 50 young adult college students were used in the analyses. Results: Results have shown moderate and strong correlations between CompCog's tasks and their equivalents considering paper and pencil tests. Items clustered in agreement with the subtest division in a principal component analysis. Conclusions: The findings suggest that CompCog is valid for measuring the cognitive processes its tasks intend to evaluate.
\end{abstract}

Keywords: reaction time, cognitive assessment screening instrument, neuropsychological tests, cognition.

\section{EVIDÊNCIA DE VALIDADE DE UMA NOVA VERSÃO DA BATERIA COMPUTADORIZADA DE RASTREIO COGNITIVO COMPCOG}

RESUMO. Embora a disponibilidade de instrumentos computadorizados para avaliação tenha aumentado ao longo dos anos, a neuropsicologia não passou por uma mudança significativa de paradigma desde a popularização do computador pessoal nos anos 1980. Para acompanhar os avanços tecnológicos da saúde e da neurociência em geral, mais esforços devem ser feitos no campo da neuropsicologia clínica para desenvolver e validar novos instrumentos de base mais tecnológica, especialmente considerando novas variáveis e paradigmas quando comparados aos testes de lápis e papel. Objetivo: 0 objetivo deste estudo foi produzir evidências de validade concorrente da nova versão da bateria computadorizada de rastreio cognitivo CompCog. Métodos: Os participantes passaram por uma sessão de avaliação neuropsicológica com testes tradicionais de lápis e papel e de outra sessão em que o CompCog foi administrado. Os dados do total de 50 jovens adultos universitários foram utilizados nas análises. Resultados: 0s resultados mostraram correlações moderadas e fortes entre as tarefas do CompCog e seus equivalentes nos testes tradicionais. Uma análise de componentes principais mostrou que os itens formaram fatores em concordância com a divisão de subtestes da bateria. Conclusões: Os resultados sugerem que o CompCog é válido para medir os processos cognitivos que suas tarefas pretendem avaliar.

Palavras-chave: tempo de reação, instrumento de triagem de avaliação cognitiva, testes neuropsicológicos, cognição.

\section{INTRODUCTION}

Tew technologies are powerful tools to aid in diagnosis and health treatments. In the clinical neuropsychological context, technology can be incorporated into the cognitive evaluation, stimulation, training, and rehabilitation. However, since the personal computer's popularization in the 1980s, neuropsychology has not gone through a significant paradigm shift. ${ }^{1}$

\footnotetext{
This study was concluded by Larissa's master studies under a double degree agreement between the Pontifícia Universidade Católica do Rio de Janeiro, Rio de Janeiro, RJ, Brazil, and the Università degli Studi di Perugia, Perugia, Italy.

'Department of Psychology, Pontifícia Universidade Católica do Rio de Janeiro - Rio de Janeiro, RJ, Brazil. Department of Philosophy, Social, Human and Education Sciences, Università degli Studi di Perugia - Perugia, Italy.

Larissa Hartle. Av. Marquês de São Vicente, 225, Casa XV - Gávea - 22541-041 Rio de Janeiro RJ - Brazil. E-mail: larissahartle@gmail.com Disclosure: The authors report no conflicts of interest.

Funding: This research was supported by the Coordenação de Aperfeiçoamento de Pessoal de Nivel Superior (CAPES) and the Conselho Nacional de Desenvolvimento Científico e Tecnológico (CNPq).
}

Received on March 20, 2021. Accepted in final form on June 20, 2021 
The availability of the computer-based assessment has increased over the years, especially over the past decade, ${ }^{2}$ but the neuropsychological testing still relies primarily on paper and pencil tasks. ${ }^{3}$ The use of computerized tests is still rare, ${ }^{1}$ and many of the efforts made to keep up with the technological advancements are related to the development of a computerized version of a traditional paper and pencil test. ${ }^{4} \mathrm{~A}$ meta-analysis found that they are usually equivalent. ${ }^{5}$ Also, there is a criticism that both are based on the theoretical concepts developed decades ago, resulting in a "cosmetic change" only. ${ }^{3}$

Some effort has also been made in the software development related to the scoring of those traditional tests. ${ }^{1}$ Thus, in general, the studies are divided into two groups: (1) the adaptation of the existing standardized tests to the computer and (2) the development of new tests and batteries for evaluating cognitive functions, which range from the design and build to the validation of new computerized instruments. The examples of some traditional and widely used neuropsychological tests that were adapted to computerized formats are the Wisconsin Card Sorting Test (WCST), ${ }^{4}$ the Category Test - a section of the Halstead-Reitan Neuropsychological Test Battery, ${ }^{6,7}$ versions of the Raven's Progressive Matrices, ${ }^{8}$ and the Corsi Block task. ${ }^{9}$

The examples among the computerized batteries that were developed for the evaluation of cognitive functions are the Automated Neuropsychological Assessment Metrics (ANAM), which evaluates attention, concentration, reaction speed, memory, mathematical ability, and decision-making; ${ }^{10}$ the Cambridge Neuropsychological Test Automated Battery (CANTAB), which evaluates working memory and planning, visuospatial memory, and attention; ${ }^{11}$ the Central Nervous System (CNS) Vital Signs (CNVS), which evaluates memory, cognitive flexibility, psychomotor speed, time, reaction, and complex attention; ${ }^{12}$ the Computerized Neuropsychological Test Battery (CNTB), which evaluates information processing, motor speed, verbal and spatial memory, attention, language, and spatial abilities; ${ }^{13}$ the Mindstreams, which evaluates memory, executive functions, attention visuospatial, verbal fluency, motor skills, and information processing ${ }^{14}$ the Cognition assessment using the NIH Toolbox, which evaluates executive function, episodic memory, language, processing speed, working memory, and attention; ${ }^{15}$ and the Computerized Neurocognitive Scanning, which evaluates executive function, memory, intellectual, and sensorimotor functions. ${ }^{16}$

But to keep up with the technological advances of healthcare and cognitive neuroscience, in general, more efforts must be made in the field of clinical neuropsychology to develop and validate new and more technology-based instruments considering variables known to be valuable and that technology made it possible to use such as processing speed and reaction time. ${ }^{17}$ The paper and pencil neuropsychological tests hardly have precise reaction time measurements, but this is an advantage that stands out among computerized tests: specific and complex variables, such as reaction time, can be measured even in milliseconds..$^{18}$ Reaction time is a variable that seems to be affected throughout many types of neurodegenerative conditions, ${ }^{19-22}$ and the present computerized battery focuses on the reaction time as its primary measure - although it is also able to measure errors. Also, the reaction time is measured as "median reaction time" throughout all the tests, so some concerns considering variability, which have been raised, could be addressed. ${ }^{23}$ Other computerized batteries using reaction time variables already exist and presented good evidence validity. ${ }^{24}$ Still, they are available only in English and use a mean reaction time, instead of a median. In this context, this study's objective was to produce concurrent validity evidence of the novel version of the computerized cognitive screening battery CompCog. CompCog was initially called as Bateria de Testes Neuropsicológicos Computadorizados ${ }^{25}$ (BTNC; Brazilian Portuguese version). It was created using the MEL Professional version $2.0^{26}$ to evaluate anterograde episodic memory, attention, visual perception, processing time information, and short-term memory. The first study concerning it investigated the clinical markers of early Alzheimer's disease (AD). Forty individuals with mild $\mathrm{AD}$ and 73 controls, paired for age and education, were studied. The battery had six tests, and the application lasted $40 \mathrm{~min}$ on average. It was run on an IBM-PC-compatible microcomputer using a 14inch SVGA color monitor. A keypad with five buttons, labeled from 1 to 5 , was used as a response input device. The AD group showed a significantly lower percentage of a correct response on episodic memory and short-term memory and a higher latency response on all other tests when compared to controls. The receiver operating characteristic (ROC) analysis showed that episodic memory, short-term memory, and choice reaction time tests were sensitive and specific to discriminate the groups and, therefore, were the clinical markers of early AD. ${ }^{18}$

After that study, a screening version of the instrument was created. It took only $15 \mathrm{~min}$ to be administrated and was named Computerized Cognitive Screening test CompCogs. CompCogs had the same material as BTNC, was developed with MEL Professional, was run on an IBM-PC, and had the same keypad with five buttons as a response input device. The CompCogs was applied in 47 
individuals with probable mild $\mathrm{AD}$ and 97 controls. The idea was to investigate its validity for the early diagnosis of AD. CompCogs presented $91.8 \%$ sensitivity and $93.6 \%$ specificity for $\mathrm{AD}$ diagnosis using the ROC analysis of $\mathrm{AD}$ diagnosis probability derived by logistic regression. It showed high validity for $\mathrm{AD}$ early diagnosis and, therefore, may be a useful alternative screening instrument. ${ }^{27}$

In 2011, CompCog was developed for mobile devices that operate on the iOS operating system, maintaining the original ideas of evaluation, but now with a new way of interaction - the touchscreen, more dynamic interface, and the possibility to be carried out in the iPad. This new version is broad and flexible. Although there is a suggested order of application, the examiner can select the tests and their order. It comprises eight tests that evaluate different cognitive domains such as information processing speed and reaction time, implicit, episodic, working memory, attention, and inhibitory control. Battery administration lasts about $40 \mathrm{~min}$ in healthy individuals.

The test is available in Portuguese, Spanish, and English. The demographical data is collected at the beginning, such as full name, age, education, sex, and handiness. The results of each test are presented at the end of each application and at the end of the whole battery. All data are stored in the cloud and are available in an Excel spreadsheet accessible through the test's website. All answers are issued using a touch screen and recorded. All tests generate reaction time measures registered in milliseconds for each touch, both as total time and as a median, to eliminate the eventual discrepant data through each test. Furthermore, correct responses' percentage, errors, and differences in reaction time between errors and correct answers are also registered. All stimuli tests are visuospatial, except for one test Stroop test, which contains written words in order to maintain the original paradigm.

\section{METHODS}

\section{Setting and participants}

The study took place at the Pontifical Catholic University of Rio de Janeiro, where the undergraduate psychology-level students were recruited and they performed the data collection at the university's psychology clinic. Participants performed a traditional paper and pencil neuropsychological testing session and another session where CompCog was administrated.

Initially, 64 young adults were selected. However, 14 were excluded: 10 for psychiatric disorders, 1 for a neurological disorder, 2 for metabolic disorders, and 1 for drug use. Thus, the data of a total of 50 participants were used in the analyses of concurrent validity evidence. The mean age in years was 21.18 (4.02), and they had a mean of 13.5 (1.7) years of schooling, being $86 \%$ women.

\section{Materials}

\section{CompCog}

This research used the test's standard tasks' order in Portuguese during the data collection phase. Tests are explained, with their variables and cognitive functions assessed, in Table 1.

\section{Paper and pencil tests}

The neuropsychological assessment was performed through a paper and pencil battery that included traditional tests commonly used in clinical neuropsychology in Brazil. Tests used and their variables are shown in Table 2.

\section{Equivalence}

The cognitive measures assessed through the traditional tests were compared to the ones evaluated by $\mathrm{CompCog}$ tasks, as shown in Table 3.

\section{Ethics}

This study was registered at the university's Ethics Research Committee and authorized by the 2012-31 Favorable Opinion. The volunteers participated in the study by signing a free and informed consent form, according to resolution 196/96 of Brazil's National Health Council, which deals with the guidelines and standards for research involving human subjects. Participation in this survey was voluntary, so they did not receive any payment. The study did not bring any risk to volunteers' health, and they could refuse and/or withdraw consent to participate in the study at any time.

\section{Statistical methods}

All data entry and analysis were carried out using SPSS Windows 22.0. Pearson's correlations were run between traditional paper and pencil variables and CompCog variables. The $\mathrm{p}$-values under 0.05 were considered to show statistical significance. A principal component analysis (PCA) with oblimin rotation (delta $=0$ ) was conducted on all items regarding time measures. Components were extracted based on eigenvalues of more than 1 . Since the size sample was small, we used the Kaiser-Meyer-Olkin (KMO) measure to verify the sampling adequacy for the analysis. KMO was 0.662 , above the level of 0.5 for adequacy. Bartlett's test of sphericity $\left(\chi^{2}(300)=1658.970\right.$, $\mathrm{p}<0.001)$ indicated that correlations between items were sufficiently large for PCA. 
Table 1. CompCog test's variables.

\begin{tabular}{|c|c|c|}
\hline Test & Cognitive functions involved and how they are evaluated & Variables \\
\hline $\begin{array}{l}\text { Simple Reaction } \\
\text { Time }\end{array}$ & $\begin{array}{l}\text { Processing speed. As soon as a white square appears in the middle of the } \\
\text { screen, the person should touch the rectangle in the bottom of the screen. }\end{array}$ & Median reaction time, total time \\
\hline $\begin{array}{l}\text { Choice Reaction } \\
\text { Time }\end{array}$ & $\begin{array}{l}\text { Processing speed. As a white or orange square appears in the middle } \\
\text { of the screen, the person should touch the rectangle of the same } \\
\text { color in the bottom of the screen. }\end{array}$ & Median reaction time, total time, correct answers \\
\hline $\begin{array}{l}\text { Implicit Learning } \\
\text { Test }\end{array}$ & $\begin{array}{l}\text { Implicit learning. As } 1 \text { of } 10 \text { gray squares distributed in the screen } \\
\text { turns white, the person must press it. There is a fixed sequence of } \\
25 \text { squares that is repeated four times (sequence 1-4) and one last } \\
\text { random sequence for control (sequence 5). }\end{array}$ & $\begin{array}{l}\text { Implicit learning (median reaction time in sequence } \\
4 \text { - median reaction time in sequence } 1 \text { ) and implicit } \\
\text { learning interference (median reaction time in } \\
\text { sequence } 5 \text { - median reaction time in sequence } 1 \text { ) }\end{array}$ \\
\hline $\begin{array}{l}\text { Visual and Spatial } \\
\text { Short-Term Memory }\end{array}$ & $\begin{array}{l}\text { Working memory. There are } 10 \text { gray squares distributed on the } \\
\text { screen. One will become white at a time, making a sequence that } \\
\text { must be reproduced. }\end{array}$ & $\begin{array}{c}\text { Correct answers, direct order SPAN, reaction time } \\
\text { in direct order, inverse order SPAN, reaction time in } \\
\text { direct order }\end{array}$ \\
\hline $\begin{array}{l}\text { Face Recognition } \\
\text { and Memory }\end{array}$ & $\begin{array}{c}\text { Episodic memory. A total of } 10 \text { drawings of unknown faces are } \\
\text { presented for } 30 \mathrm{~s} \text {. Then, the participant should choose, between } \\
10 \text { pairs of faces, which one was among those initially shown for } \\
\text { memorization in } 4 \text { attempts. }\end{array}$ & $\begin{array}{l}\text { Total time and correct answers, and median reaction } \\
\text { time and correct answers for each of the four tasks. }\end{array}$ \\
\hline $\begin{array}{l}\text { Inhibitory Control } \\
\text { Test }\end{array}$ & $\begin{array}{l}\text { Attention, Inhibitory control Squares of different colors will appear in the } \\
\text { middle of the screen for } 1 \mathrm{~s} \text { each, the white ones should be avoided. }\end{array}$ & $\begin{array}{l}\text { Total time, median reaction time, correct answer median } \\
\text { reaction time, error's median reaction time and errors }\end{array}$ \\
\hline Stroop Test & $\begin{array}{l}\text { Attention, Inhibitory control. All tasks have four colored rectangles } \\
\text { located at the bottom of the screen. The person should touch the one } \\
\text { matching the stimuli that appear in the middle of the screen considering } \\
\text { its color without (task 1) and with distracters (tasks } 2 \text { and } 3 \text { ). }\end{array}$ & $\begin{array}{c}\text { Total time, interference, median reaction time and } \\
\text { errors for each of the three tasks }\end{array}$ \\
\hline Survey Test & $\begin{array}{l}\text { Attention. Squares of different colors will appear in the middle of the } \\
\text { screen for } 1 \mathrm{~s} \text { each. Participants should press the white ones on the first } \\
\text { tasks, white and blue ones on the second, and yellow ones on the third. }\end{array}$ & $\begin{array}{l}\text { Median reaction time and correct answers for each of } \\
\text { the three tasks }\end{array}$ \\
\hline
\end{tabular}

Table 2. Traditional test's variables.

\begin{tabular}{|c|c|c|}
\hline Test & Cognitive functions involved & Variables \\
\hline TEACO-FF & Attention, Processing speed & Total score \\
\hline TECON 1 & Attention, Processing speed & Total score \\
\hline Stroop Test & Attention, Inhibitory control & $\begin{array}{l}\text { Errors and time to completion in each task, } \\
\text { interference }\end{array}$ \\
\hline Color Trails Test & Attention, Inhibitory control & Time to completion in each task, interference \\
\hline WAIS-III processing speed index & Attention, Processing speed & Coding, Symbol Search, Processing Speed Index \\
\hline WAIS-III working memory index & Working memory & $\begin{array}{l}\text { Arithmetic, Digit SPAN and Letter-Number } \\
\text { Sequencing, Working Memory Index, direct order } \\
\text { SPAN, inverse order SPAN }\end{array}$ \\
\hline Rey Auditory Verbal Learning Test & Episodic memory & $\begin{array}{l}A 1, A 2, A 3, A 4, A 5, A 6, A 7, B 1 \text {, proactive interference, } \\
\text { retroactive interference, forgetful speed, recognition }\end{array}$ \\
\hline Rey-0sterrieth Complex Figure Test & Episodic memory & Total score and time to completion in copy and recall \\
\hline Wisconsin Card Sorting Test & Implicit learning & $\begin{array}{l}\text { Number of categories completed, trials to complete } \\
\text { first category, failure to maintain set, learning to learn }\end{array}$ \\
\hline R-1 Test & Implicit learning & Total score \\
\hline
\end{tabular}


Table 3. Cognitive functions measured by traditional tests and predicted equivalents.

\begin{tabular}{|c|c|c|}
\hline Cognitive function & Traditional tests & CompCog tests \\
\hline Attention & $\begin{array}{l}\text { TEACO-FF, TECON 1, Stroop Test, Color Trails Test, } \\
\text { WAIS-III processing speed index }\end{array}$ & Inhibitory Control Test, Stroop Test, Survey Test \\
\hline Working memory & $\begin{array}{l}\text { WAIS-III working memory index (Arithmetic, Digit Span, } \\
\text { and Letter-Number Sequencing). }\end{array}$ & Visual And Spatial Short-Term Memory \\
\hline Episodic memory & $\begin{array}{c}\text { Rey Auditory Verbal Learning Test, Rey-0sterrieth } \\
\text { Complex Figure Test }\end{array}$ & Face Recognizing And Memory \\
\hline Implicit learning & Wisconsin Card Sorting Test, R-1 Test & Implicit Learning Test \\
\hline Inhibitory control & Stroop Test, Color Trails Test & Inhibitory Control Test, Stroop Test \\
\hline Processing speed & $\begin{array}{l}\text { TEACO-FF, TECON 1, WAIS-III processing speed index } \\
\text { (Digit Symbol-Coding and Symbol Search) }\end{array}$ & Simple Reaction Time, Choice Reaction Time \\
\hline
\end{tabular}

\section{RESULTS}

Results have shown moderate and strong correlations between CompCog's tasks and their equivalents considering paper and pencil tests. The results of the correlations are shown in Table 4, regarding comparisons reported in Table 1 with variables reported in Tables 2 and 3. Participant's performance in each test are reported in Table 5. Regarding the PCA, Table 6 shows the pattern matrix, with extracted components' loadings (i.e., regression coefficients) after oblimin rotation. The Phi matrix is reported in Table 7. In general, each subtest's items - except for items of Simple Reaction Time and Choice Reaction Time, which clustered together - loaded on the same component, generating seven components in total.

\section{DISCUSSION}

Findings suggest that CompCog is valid for measuring the cognitive processes its tasks intend to evaluate. Regarding PCA's results, the items of each subtest were loaded on the same component. This suggests that each component represents one test that do not overlap, except for Simple Reaction Time and Choice Reaction Time, which are loaded together. The correlations between components' scores, as shown in Table 7, were also low. Three variables deserve further discussion: Error's median reaction time of Inhibitory control test; Median reaction time in 1st task of the Stroop Test; and Implicit learning interference of Implicit learning test.

The latter could be placed in different components, with the possibility of being included together with the other variable of the Implicit learning test. Other options are in the Survey component and Stroop component. Actually, the variable is a control measure for the Implicit learning test (Table 1 ) and uses some of the same cognitive functions of the components where it loaded. The same can be said about the Median reaction time in 1 st task of the Stroop Test. The variable could be placed in three components, including altogether with the other variables of the same test. The 1st task of the Stroop Test does not involve the Stroop effect yet, and it is a measure of attention and used also to calculate the interference. The last variable worth discussing is the Error's median reaction time of Inhibitory control test. It loaded together with Stroop Test's variables. One possibility to explain this item loading component is that errors might create a different pattern when compared to correct answers the majority of measures in this study. Error's reaction time and what this type of measure can tell us might be something worth exploring in future studies.

Also, the results have shown moderate correlations $(0.30<r<0.49)$ and strong correlations $(r>0.5)(28)$ between CompCog's tasks and their equivalents considering paper and pencil tests. Some factors can explain the small number of strong correlations. First, it is important to highlight the differences between both assessments used. Besides all the particularities that computerized tests have in relation to paper and pencil tasks, CompCog is highly dependent on visual and motor stimuli, something unusual when considering traditional cognitive tasks that rely on paper, pencil, and oral interactions. Other studies that aimed to produce concurrent validity evidence of computerized tests comparing it to traditional analogous tests had the same results. ${ }^{29,30}$ Second, the target group to which CompCog was designed, i.e., elderly and $\mathrm{AD}$ patients, ${ }^{18}$ is not the same group that composed the study sample. This brought some facilities to the study realization and comparisons, such as higher subjects' availability and normal cognitive performance in both batteries, but it 


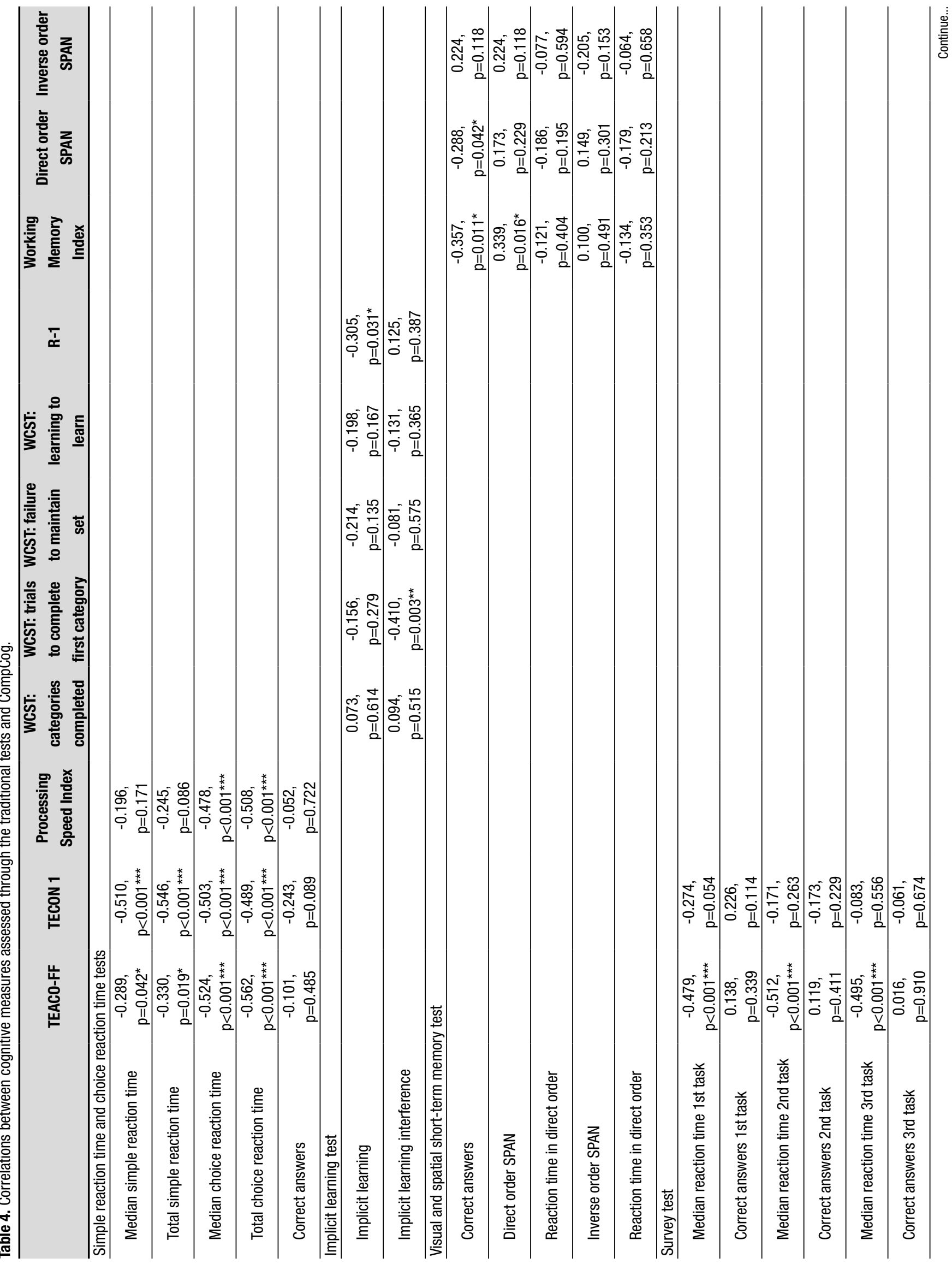




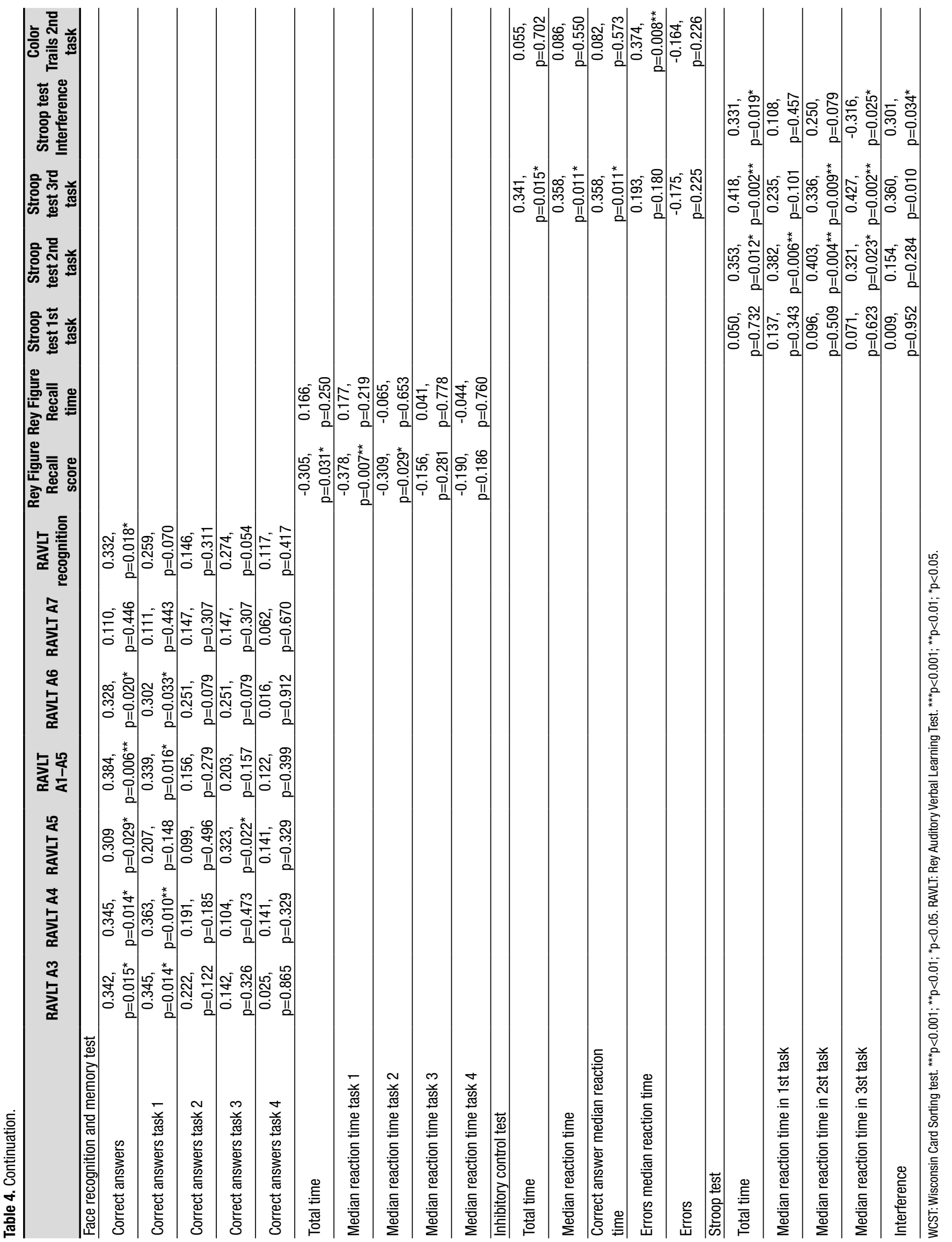


Table 5. Participants' performance in each test.

\begin{tabular}{|c|c|c|c|}
\hline & M (SD) & Minimum & Maximum \\
\hline \multicolumn{4}{|l|}{ Face recognition and memory test } \\
\hline Correct answers & $99.550(1.400)$ & 92.5 & 100.0 \\
\hline Correct answers task 1 & $98.800(4.798)$ & 70.0 & 100.0 \\
\hline Correct answers task 2 & $100.0(000)$ & $100 . .0$ & 100.0 \\
\hline Correct answers task 3 & $99.800(1.414)$ & 90.0 & 100.0 \\
\hline Correct answers task 4 & $99.600(1.979)$ & 90.0 & 100.0 \\
\hline Total time & $49.518(6.452)$ & 37.430 & 72.544 \\
\hline Median reaction time task 1 & $1393.089(230.010)$ & 981.453 & 2214.585 \\
\hline Median reaction time task 2 & $1149.122(146.242)$ & 874.565 & 1687.089 \\
\hline Median reaction time task 3 & $1093.336(144.033)$ & 825.360 & 1495.029 \\
\hline Median reaction time task 4 & $1032.570(135.619)$ & 855.314 & 1567.207 \\
\hline \multicolumn{4}{|l|}{ Inhibitory control test } \\
\hline Total time & $62.038(4.760)$ & 49.838 & 74.377 \\
\hline Median reaction time & $515.917(54.208)$ & 424.277 & 650.189 \\
\hline Correct answer median reaction time & $517.0917(53.719)$ & 425.139 & 650.189 \\
\hline Errors median reaction time & $421.378(330.271)$ & 000.000 & 1001.523 \\
\hline Errors & $1.760(1.697)$ & 0.0 & 8.0 \\
\hline \multicolumn{4}{|l|}{ Stroop test } \\
\hline Total time & $239.458(25.960)$ & 202.829 & 336.983 \\
\hline Median reaction time in 1st task & $696.272(44.247)$ & 629.101 & 786.947 \\
\hline Median reaction time in 2 st task & $767.973(71.369)$ & 646.200 & 1013.842 \\
\hline Median reaction time in 3st task & $808.564(104.696)$ & 662.537 & 1197.787 \\
\hline Interference & $1.161(0.133)$ & 0.994 & 1.690 \\
\hline \multicolumn{4}{|l|}{ Simple and choice reaction time tests } \\
\hline Median simple reaction time & $345.527(81.091)$ & 217.987 & 554.009 \\
\hline Total simple reaction time & $36.192(8.694)$ & 25.36 & 60.34 \\
\hline Median choice reaction time & $525.327(60.003)$ & 434.597 & 737.471 \\
\hline Total choice reaction time & $53.736(6.317)$ & 43.99 & 74.77 \\
\hline Correct answers & $96.800(2.329)$ & 91.0 & 100.0 \\
\hline \multicolumn{4}{|l|}{ Implicit learning test } \\
\hline Implicit learning & $-61.292(46.071)$ & -192.904 & 15.166 \\
\hline Implicit learning interference & $-3.641(26.631)$ & -96.040 & 32.97 \\
\hline \multicolumn{4}{|l|}{ Visual and spatial short-term memory test } \\
\hline Correct answers & $78.260(6.075)$ & 65.26 & 90.24 \\
\hline Correct answers 3rd task & $96.040(3.294)$ & 88.0 & 100.0 \\
\hline
\end{tabular}


Table 5. Continuation.

\begin{tabular}{|c|c|c|c|}
\hline & $M(S D)$ & Minimum & Maximum \\
\hline Direct order SPAN & $5.700(1.182)$ & 3.0 & 8.0 \\
\hline Reaction time in direct order & $519.482(128.787)$ & 271.614 & 871.155 \\
\hline Inverse order SPAN & $4.680(1.168)$ & 1.0 & 7.0 \\
\hline Reaction time in direct order & $522.952(111.046)$ & 335.266 & 878.779 \\
\hline \multicolumn{4}{|l|}{ Survey test } \\
\hline Median reaction time 1st task & $544.128(61.712)$ & 438.921 & 681.443 \\
\hline Correct answers 1st task & $99.360(1.481)$ & 94.0 & 100.0 \\
\hline Median reaction time 2 nd task & $535.730(48.314)$ & 458.359 & 667.748 \\
\hline Correct answers 2nd task & $99.120(1.814)$ & 92.0 & 100.0 \\
\hline Median reaction time 3rd task & $528.489(47.660)$ & 424.811 & 633.226 \\
\hline Correct answers 3rd task & $96.040(3.294)$ & 88.0 & 100.0 \\
\hline
\end{tabular}

also created a ceiling effect in some tasks that may have influenced the analyses. The high diagnostic accuracy reported in other studies is, itself, another evidence of the validity of CompCog's tasks. ${ }^{18,27}$

\section{Simple reaction time and choice reaction time}

Both tests assess processing speed and attention, and its variables were correlated to TEACO-FF, TECON 1, and WAIS Processing Speed Index. The correlations are negative because CompCog measures are provided in time, while the analogous tests have the variables of correct answers. Choice Reaction Time seems to be a better measure of processing speed than the Simple Reaction Time. An explanation is a possibility of creating an automatic pattern of hitting the screen in the Simple Reaction Time test, something that cannot be performed in the Choice Reaction Time as it involves a choice between options.

\section{Implicit learning test}

There are not many traditional paper and pencil tests that specifically measure implicit learning, possibly due to the difficulty of assessing this cognitive function through paper and pencil tests. Nevertheless, WCST and R-1 Test are the options that, even though not primarily, involve implicit processes. ${ }^{31,32}$ CompCog's implicit learning variable was correlated with $R-1$ score $(r=-0.305$, $\mathrm{p}=0.031)$. R-1 involves insight and implicit perception, ${ }^{31}$ as the implicit learning variable also does. The correlation is negative because the smaller the variable is, the higher the implicit learning. The implicit learning interference measured through CompCog had a significant negative correlation with WCST variable trials to complete first category ( $\mathrm{r}=-0.410, \mathrm{p}=0.003)$. This can be explained as the process to learn the rule to complete the first category in WCST involves implicit learning. ${ }^{32}$ The more trials one needs to complete the category in WCST, the less implicit learning happened in the CompCog task, the smaller the interference of this learning when completing the last sequence. The other variables suffer less influence of implicit learning, being this probably the explanation for the absence of other correlations.

\section{Visual and spatial short-term memory}

There were almost no correlations between CompCog's short-memory task and short-memory traditional paper and pencil tests. However, it is important to notice that the CompCog's task is based on the visual and spatial stimuli, while WAIS-III variables are based on the auditory stimuli. It is widely accepted that, although there is a common component for both stimuli processing in working memory (i.e., central executive), ${ }^{33}$ there are different processing pathways for each one of them. Auditory stimuli should be processed in the Phonological Loop, and the visual and spatial stimuli, in the Visuospatial Sketchpad, ${ }^{33}$ making both tests challenging to compare.

\section{Face recognition and memory}

The tasks of Rey Auditory Verbal Learning Test (RAVLT) and CompCog had moderate correlations regarding only the first CompCog's task and the correct answers' total percentage. An explanation for the lack of correlations between the other tasks and RAVLT variables is the ceiling effect seen on the computerized test. As it was developed considering the memory capacity of elderly 
Table 6. Pattern matrix.

$\begin{array}{llllllll}1 & 2 & 3 & 4 & 5 & 6 & 7\end{array}$

Face recognition and memory test

\begin{tabular}{|c|c|c|c|c|c|c|c|}
\hline Total time & 0.089 & 0.937 & 0.063 & -0.004 & 0.002 & 0.044 & 0.081 \\
\hline Median reaction time task 1 & -0.081 & 0.899 & -0.006 & -0.062 & -0.083 & 0.098 & 0.170 \\
\hline Median reaction time task 2 & -0.056 & 0.781 & 0.065 & -0.074 & 0.203 & 0.152 & -0.229 \\
\hline Median reaction time task 3 & 0.118 & 0.693 & 0.280 & 0.053 & 0.161 & 0.017 & -0.141 \\
\hline Median reaction time task 4 & 0.140 & 0.676 & -0.071 & -0.017 & 0.140 & -0.343 & 0.050 \\
\hline \multicolumn{8}{|l|}{ Inhibitory control test } \\
\hline Total time & -0.110 & 0.115 & 0.952 & -0.060 & -0.074 & 0.083 & 0.062 \\
\hline Median reaction time & 0.007 & 0.041 & 0.955 & -0.076 & 0.000 & -0.078 & -0.059 \\
\hline Correct answer median reaction time & 0.013 & 0.057 & 0.951 & -0.056 & -0.010 & -0.086 & -0.068 \\
\hline Errors median reaction time & 0.462 & -0.075 & -0.139 & -0.364 & -0.046 & -0.038 & 0.105 \\
\hline \multicolumn{8}{|l|}{ Stroop test } \\
\hline Total time & 0.925 & 0.016 & 0.094 & -0.044 & 0.060 & 0.055 & -0.030 \\
\hline Median reaction time in 1st task & 0.379 & -0.139 & 0.269 & -0.353 & 0.427 & 0.423 & -0.062 \\
\hline Median reaction time in 2 st task & 0.854 & -0.031 & 0.083 & -0.121 & 0.125 & 0.123 & -0.062 \\
\hline Median reaction time in 3st task & 0.878 & 0.121 & 0.039 & 0.075 & 0.089 & -0.141 & -0.064 \\
\hline Interference & 0.783 & 0.196 & -0.090 & 0.278 & -0.134 & -0.400 & -0.037 \\
\hline \multicolumn{8}{|l|}{ Simple and choice reaction time tests } \\
\hline Median simple reaction time & -0.031 & 0.032 & 0.142 & -0.911 & 0.019 & -0.008 & 0.044 \\
\hline Total simple reaction time & 0.035 & 0.085 & 0.130 & -0.912 & -0.018 & -0.016 & 0.064 \\
\hline Median choice reaction time & 0.404 & 0.334 & 0.028 & -0.536 & 0.034 & -0.022 & 0.053 \\
\hline Total choice reaction time & 0.456 & 0.306 & 0.045 & -0.502 & 0.019 & -0.009 & 0.060 \\
\hline \multicolumn{8}{|l|}{ Implicit learning test } \\
\hline Implicit learning & -0.118 & 0.061 & -0.044 & -0.103 & 0.141 & -0.064 & 0.913 \\
\hline Implicit learning interference & 0.179 & -0.034 & 0.218 & 0.522 & -0.101 & 0.487 & 0.319 \\
\hline \multicolumn{8}{|l|}{ Visual and spatial short-term memory test } \\
\hline Reaction time in direct order & 0.006 & 0.116 & -0.064 & -0.043 & 0.856 & -0.073 & -0.029 \\
\hline Reaction time in direct order & -0.042 & 0.037 & -0.067 & 0.152 & 0.946 & -0.048 & 0.149 \\
\hline \multicolumn{8}{|l|}{ Survey test } \\
\hline Median reaction time 1st task & 0.222 & -0.065 & 0.110 & -0.111 & 0.151 & -0.745 & 0.087 \\
\hline Median reaction time 2 nd task & 0.117 & -0.153 & 0.301 & -0.074 & 0.184 & -0.740 & 0.054 \\
\hline Median reaction time 3rd task & 0.168 & -0.078 & 0.555 & 0.135 & 0.038 & -0.509 & 0.076 \\
\hline
\end{tabular}

Values in bold indicate the variables included in each component. 
Table 7. Phi matrix.

\begin{tabular}{|c|c|c|c|c|c|c|c|}
\hline & 1 & 2 & 3 & 4 & 5 & 6 & 7 \\
\hline 1 & 1.000 & 0.223 & 0.251 & -0.268 & 0.235 & -0.235 & 0.042 \\
\hline 2 & & 1.000 & 0.176 & -0.181 & 0.262 & -0.029 & 0.018 \\
\hline 3 & & & 1.000 & -0.108 & 0.201 & -0.059 & 0.024 \\
\hline 4 & & & & 1.000 & -0.251 & 0.040 & 0.024 \\
\hline 5 & & & & & 1.000 & -0.146 & 0.015 \\
\hline 6 & & & & & & 1.000 & 0.019 \\
\hline 7 & & & & & & & 1.000 \\
\hline
\end{tabular}

and $\mathrm{AD}$ patients, university students could quickly learn the stimuli presented in the first try, creating an almost constant variable on the subsequent tasks. Besides it, RAVLT involves auditory stimuli while CompCog considers the memory of visual stimuli. Rey Figure Test, instead, assesses visual memory, but it is a test that suffers a lot of influence of executive functions, ${ }^{34}$ which does not happen in CompCog. Even so, the moderated correlations were found between the recall score of Rey Figure Test and the median reaction time of the computerized test's 1st and 2nd tasks. Again, the ceiling effect may have contributed to the lack of correlations regarding the other two tasks.

\section{Inhibitory control test}

Inhibitory control is an executive function that requires the inhibition of automatic processes in order to activate controlled processes. This cognitive function is evaluated in Stroop's 3rd task and Color Trails test, with which CompCog's Inhibitory Control Test had moderated correlations. Total time, median reaction time, and correct answer's median reaction time were correlated with Stroop's 3rd task. This makes sense since the last task needs more time to be completed if they take a longer time to produce their answers due to slower processing related to inhibitory control. Instead, Error's median reaction time was correlated with Color Trails' 2nd task. A more significant Error's median reaction time shows a situation where inhibitory control actually did not work out. The same can be said about time to completion in Color Trails' 2nd task.

\section{Stroop test}

Stroop's paper and pencil test and its computerized version are both based on the same paradigm. Even so, there are still some differences between both versions. Correlations were found between the 2 nd task of each presentation, 3rd task, and interference. An explanation for the lack of correlation between the 1st tasks - the only one not correlated - is that the paper and pencil version is more an automatic process - naming colors - than the computerized version. The latter involves the time to choose between the colors' buttons at the bottom of the screen, which is less automatic than naming.

\section{Survey test}

Survey is a component of attention and was mainly correlated to TEACO-FF, the traditional test most related to the CompCog's survey test. Both involve the survey for a simple stimulus (one figure or colors). The correlation is negative because the CompCog's test is measured through time - the smaller, the better — and the paper and pencil test is measured through correct answers the higher, the better. TECON 1 did not present correlations with the computerized test, possibly due to the higher complexity of the stimulus that has to be searched, what demands working memory, and divided attention besides survey capacity.

A limitation of this study is, as already mentioned, the differences between the characteristics of the sample used in this study and the population to which CompCog was created to. ${ }^{18}$ Nevertheless, the chosen sample brought benefits, too, such as preserved cognitive abilities to assess and compare the processes underneath each neuropsychological test. The differences between both assessments - computerized and paper and pencil - can also be considered as a limitation, but, at the same time, it is the option available to assess the concurrent validity of new computerized neuropsychological batteries. Nevertheless, the high number of measures based on reaction time and total time is an important advantage of CompCog and other computerized tests. The precise measurement given by time variables, with high sensibility and results with millisecond precision, is even more accurate than correct answers to evaluate cognitive processes, ${ }^{19}$ as it may assess subtle changes in cognition that might not have impacted the outcome yet. Moreover, the PCA supported the differentiation between cognitive domains measured by the subtests of the battery. In conclusion, the results suggest that CompCog is a valid measure of memory, attention, implicit learning, inhibitory control, and processing speed.

Authors' contributions. LH, LMS and HF: conceptualization. LH, LMS and ED: data curation. LH and LMS: investigation. GB and HF: methodology. HF: validation and project administration. LH: formal analysis. LH and LMS: writing-original draf. LH, EB, GB and HF: writing-review \& editing. GB and HF: supervision. 


\section{REFERENCES}

1. Miller J, Barr W. The technology crisis in neuropsychology. Arch Clin Neuropsychol. 2017;32(5):541-54. https://doi.org/10.1093/arclin/acx050

2. Casaletto KB, Heaton RK. Neuropsychological assessment: past and future. J Int Neuropsychol Soc. 2017;23(9-10 Special Issue):778-90. https://doi.org/10.1017/S1355617717001060

3. Rabin LA, Spadaccini AT, Brodale DL, Grant KS, Elbulok-Charcape MM, Barr WB. Utilization rates of computerized tests and test batteries among clinical neuropsychologists in the United States and Canada. Prof Psychol Res Pract. 2014;45(5):368-77. https://doi.org/10.1037/a0037987

4. Heaton RK, PAR Staff. Wisconsin Card SortingTest: Computer version 4, research edition (WCST: CV4).Odessa, FL: Psychological Assessment Resources; 2003.

5. Mead AD, Drasgow F. Equivalence of Computerized and Paper-and-Pencil Cognitive Ability Tests: A Meta-Analysis. Psychol Bull. 1993;114(3):449-58. https://doi.org/10.1037/0033-2909.114.3.449

6. Beaumont JG. The validity of the category test administered by on-line computer. J Clin Psychol. 1975;31(3):485-462. https://doi.org/10.1002/ 1097-4679(197507)31:3<458::AID-JCLP2270310320>3.0.CO;2-।

7. Browndyke JN. The remote neuropsychological assessment-category test: Development and validation of a computerized, Internet-based neuropsychological assessment measure. LSU Hist Diss These. 2001;267:1-193.

8. French CC, Beaumont JG. A clinical study of the automated assessment of intelligence by the Mill Hill vocabulary test and the standard progressive matrices test. J Clin Psychol. 1990;46(2):129-40. https://doi.org/10.1002/ 1097-4679(199003)46:2<129::aid-jclp2270460203>3.0.co;2-y

9. Guevara MA, Sanz-Martin A, Hernández-González M, Sandoval-Carrillo IK. CubMemPC: prueba computarizada para evaluar la memoria a corto plazo visoespacial con y sin distractores. Rev Mex Ing Biomed. 2014;35(2):175-86

10. Kabat $\mathrm{MH}$, Kane RL, Jefferson AL, DiPino RK. Construct validity of selected Automated Neuropsychological Assessment Metrics (ANAM) battery measures. Clin Neuropsychol. 2001;15(4):498-507. https://doi. org/10.1076/clin.15.4.498.1882

11. Robbins TW, James M, Owen AM, Sahakian BJ, Mclnnes L, Rabbitt P Cambridge neuropsychological test automated battery (CANTAB): A factor analytic study of a large sample of normal elderly volunteers. Dementia. 1994:5(5):266-81. https://doi.org/10.1159/000106735

12. Gualtieri CT, Johnson LG. Reliability and validity of a computerized neurocognitive test battery, CNS Vital Signs. Arch Clin Neuropsychol. 2006;21:623-43. https://doi.org/10.1016/j.acn.2006.05.007

13. Cutler NR, Shrotriya RC, Sramek JJ, Veroff AE, Seifert RD, Reich LA, et al. The Use of the Computerized Neuropsychological Test Battery (CNTB) in an efficacy and safety trial of BMY 21,502 in Alzheimer's Disease. Ann N Y Acad Sci. 1993;695(1):332-6. https://doi.org/10.1111/j.1749-6632.1993.tb23079.x

14. Dwolatzky T, Whitehead V, Doniger G, Simon E, Schweiger A, Jaffe D, et al. Validity of a novel computerized cognitive battery for mild cognitive impairment. BMC Geriatr. 2003;3(1):4. https://doi.org/10.1186/14712318-3-4

15. Weintraub S, Dikmen SS, Heaton RK, Tulsky DS, Zelazo PD, Bauer PJ, et al. Cognition assessment using the NIH Toolbox. Neurology. 2013;80(11 Suppl 3):S54-64. https://doi.org/10.1212/WNL.0b013e3182872ded

16. Gur RC, Ragland JD, Moberg PJ, Turner TH, Bilker WB, Kohler C, et al Computerized neurocognitive scanning: I. Methodology and validation in healthy people. Neuropsychopharmacology. 2001;25(5):766-76. https:// doi.org/10.1016/S0893-133X(01)00278-0
17. Martorelli M, Hartle L, Coutinho G, Mograbi D, Chaves D, Silberman C et al. Diagnostic accuracy of early cognitive indicators in mild cognitive impairment. Dement Neuropsychol. 2020;14(4):358-65. https://doi. org/10.1590/1980-57642020dn14-040005

18. Charchat H, Nitrini R, Caramelli P, Sameshima K. Investigação de Marcadores clínicos dos estágios iniciais da doença de Alzheimer com testes neuropsicológicos computadorizados. Psicol Reflex Crit. 2001;14(2):30516. https://doi.org/10.1590/S0102-79722001000200006

19. Salthouse TA. Aging and measures of processing speed. Biol Psychol. 2000;54:35-54. https://doi.org/10.1016/s0301-0511(00)00052-1

20. Giovannetti T, Bettcher BM, Brennan L, Libon DJ, Kessler RK, Duey K. Coffee with jelly or unbuttered toast: commissions and omissions are dissociable aspects of everyday action impairment in Alzheimer's disease. Neuropsychology. 2008;22(2):235-45. https://doi.org/10.1037/0894-4105.22.2.235

21. Phillips M, Rogers P, Haworth J, Bayer A, Tales A. Intra-individual reaction time variability in mild cognitive impairment and Alzheimer's disease: gender, processing load and speed factors. PLoS One. 2013;8(6). https:// doi.org/10.1371/journal.pone.0065712

22. Andriuta D, Diouf M, Roussel M, Godefroy $O$. Is reaction time slowing an early sign of Alzheimer's disease? A meta-analysis. Dement Geriatr Cogn Disord. 2019;47(4-6):281-8. https://doi.org/10.1159/000500348

23. Germine L, Reinecke K, Chaytor NS. Digital neuropsychology: Challenges and opportunities at the intersection of science and software. Clin Neuropsychol. 2019;33(2):271-86. https://doi.org/10.1080/13854046.2018.1535662

24. Moore TM, Basner M, Nasrini J, Hermosillo E, Kabadi S, Roalf DR, et al. Validation of the cognition test battery for spaceflight in a sample of highly educated adults. Aerosp Med Hum Perform. 2017;88(10):937-46. https:// doi.org/10.3357/AMHP.4801.2017

25. Charchat H. Desenvolvimento de uma bateria de testes neuropsicológicos computadorizados para o diagnóstico precoce da Doença de Alzheimer [unpublished master thesis]. São Paulo: Universidade de São Paulo; 1999.

26. Schneider W. Mel Professional User's Guide. Pittsburgh: Psychology Software Tools; 1995.

27. Fichman HC, Nitrini R, Caramelli P, Sameshima K. A new Brief computerized cognitive screening battery (CompCogs) for early diagnosis of Alzheimer's disease. Dement Neuropsychol. 2008;2(1):13-9. https://doi. org/10.1590/S1980-57642009DN20100004

28. Cohen J. Quantitative methods in psychology. Psychol Bull. 1992;112(1):155-9. https://doi.org/10.1037//0033-2909.112.1.155

29. Elwood RW. MicroCog: assessment of cognitive functioning. Neuropsychol Rev. 2001;11(2):89-100. https://doi.org/10.1023/a:1016671201211

30. Matos Gonçalves M, Pinho MS, Simões MR. Construct and concurrent validity of the Cambridge neuropsychological automated tests in Portuguese older adults without neuropsychiatric diagnoses and with Alzheimer's disease dementia. Aging, Neuropsychol Cogn. 2018;25(2):290-317. https://doi.org/10.1080/13825585.2017.1294651

31. Noronha APP, Sisto FF, Santos AA. Teste de inteligência R1 - Forma B E G36 : criterion validity evidences. Psicol Argum. 2005;23(42):41-6. https:// doi.org/10.7213/rpa.v23i42.19925

32. Starkstein SE, Sabe L, Cuerva AG, Kuzis G, Leiguarda R. Anosognosia and procedural learning in Alzheimer's disease. Neuropsychiatry Neuropsychol Behav Neurol. 1997;10(2):96-101. PMID: 9150509

33. Baddeley A. Exploring the central executive. Q J Exp Psychol Sect A Hum Exp Psychol. 1996;49(1):5-28. https://doi.org/10.1080/713755608

34. Weber RC, Riccio CA, Cohen MJ. Does Rey Complex Figure copy performance measure executive function in children? Appl Neuropsychol Child. 2013;2(1):6-12. https://doi.org/10.1080/09084282.2011.643964 